\section{BMJ Paediatrics Open}

\title{
At risk child: a contemporary analysis of injured children in London and the South East of England: a prospective, multicentre cohort study
}

Ceri Elbourne (D) , ${ }^{1}$ Elaine Cole,${ }^{2}$ Stephen Marsh, ${ }^{3}$ Dean Rex, ${ }^{4}$ Erica Makin, ${ }^{5}$ Rebecca Salter, ${ }^{6}$ Karim Brohi, ${ }^{2,7}$ Naomi Edmonds, ${ }^{8}$ Stewart Cleeve, ${ }^{1,3}$ Breda O'Neill, ${ }^{9}$ Paediatric Evaluation of the London Trauma System (PELoTS) Collaborators

To cite: Elbourne C, Cole E, Marsh S, et al. At risk child: a contemporary analysis of injured children in London and the South East of England: a prospective, multicentre cohort study. BMJ Paediatrics Open 2021;5:e001114. doi:10.1136/ bmjpo-2021-001114

- Additional supplemental material is published online only. To view, please visit the journal online (http://dx.doi.org/ 10.1136/bmjpo-2021-001114).

Received 30 March 2021 Accepted 2 August 2021
Check for updates

(c) Author(s) (or their employer(s)) 2021. Re-use permitted under CC BY-NC. No commercial re-use. See rights and permissions. Published by BMJ.

For numbered affiliations see end of article.

Correspondence to

Dr Ceri Elbourne; cerielbourne@ gmail.com

\section{ABSTRACT}

Background Injury is a leading health burden in children yet relatively little is reported about the contemporary risks they face. Current national registry data may under-represent the true burden of injury to children. We aim to analyse contemporary patterns of paediatric trauma and identify current factors putting children at risk of injury.

Methods A 3-month prospective multicentre cohort evaluation of injured children across the London Major Trauma System was performed. All children receiving a trauma team activation; meeting National Institute for Health and Care Excellence CT head criteria; or admitted/ transferred out due to trauma were included. Data were collected on demographics, mechanism and location of injury, and body region injured. The primary outcome was in-hospital mortality and secondary outcome was safeguarding concerns.

Results 659 children were included. Young children were more likely to be injured at home ( $0-5$ years old: $70.8 \%, n=167$ vs adolescents: $15.6 \%, n=31$ ). Adolescents were more likely to be injured in the street $(42.7 \%, \mathrm{n}=85)$. Head trauma caused over half of injuries in $0-5$ years old $(51.9 \%, n=121)$. Falls were common and increasingly prevalent in younger children, causing $56.6 \%(n=372)$ of injuries. In adolescents, penetrating violence caused more than one in five injuries $(21.9 \%, \mathrm{n}=50)$. Most injured children survived ( $99.8 \%, n=658$ ), however, one in four $(26.1 \%, n=172)$ had safeguarding concerns and a quarter of adolescents had police, third sector or external agency involvement $(23.2 \%, n=53)$.

Conclusions This study describes modern-day paediatric trauma and highlights the variance in injury patterns in young children and adolescents. Importantly, it highlights differences in actual rates of injuries compared with those reported from current national registry data. We must understand real risks facing 21 st century children to effectively safeguard future generations. The results provide an opportunity to reassess the current approach to injury prevention, child and adolescent safeguarding, and public health campaigns for child safety.

\section{What is known about the subject?}

Trauma is the leading cause of death in children.

- Injury patterns vary across age groups.

- Falls are the most common cause of injuries in under 5s.

\section{What this study adds?}

- National registry criteria vastly under-represent the true volume of paediatric trauma.

- Prevalence of interpersonal violence in children and adolescents is significantly higher than previously reported.

- Traditional approaches to safeguarding must be modernised to reflect contemporary risks of interpersonal violence and avoidable harm.

\section{INTRODUCTION}

Trauma remains the leading cause of death and morbidity for children and young people. ${ }^{1}$ Historically, road-related incidents were the greatest source of death and serious injury to children. ${ }^{1}$ Contemporary mechanisms of injury are evolving, with interpersonal violence ${ }^{23}$ and falls ${ }^{45}$ overtaking as the most common causes of injury in children. Effective safeguarding of children and young people requires an accurate understanding of contemporary risk, this is essential to underpin future injury prevention strategies, if the success of those reducing road related casualties is to be replicated. ${ }^{6}$ As mechanisms of injury in children evolve, the focus of injury prevention processes must also adapt. Accurate understanding of modern-day injury patterns is therefore essential to minimise risk and enhance child safety. 
Falls, traditionally seen as a predominant cause of injury in the elderly, are now a leading mechanism in children. ${ }^{45}$ Despite this, awareness of the burden of falls for children in the UK is limited, ${ }^{7}$ especially when compared with falls prevention strategies seen in older people. Falls frequently result in head injuries in children, the impact of which is subject to a growing body of evidence detailing the cognitive and socioeconomic impacts of even mild traumatic brain injury in early years. ${ }^{8}$

Contemporary reports also reveal a rise in violence related injury in both young adult ${ }^{2}$ and paediatric populations, ${ }^{910}$ however, current violence reduction strategies focus mainly on young adults. ${ }^{311}$ In 2018 , a single centre study in London found a penetrating injury rate of $9.4 \%$ in under 16 s. $^{2}$ Yet in the same year, national trauma data suggested just $6 \%$ of injured children aged 16 or less suffered penetrating injuries in London. ${ }^{12}$ These data may under-represent the true incidence of paediatric violence-related injury due to the volume of cases not currently meeting Trauma Audit Research Network (TARN) national registry inclusion criteria. Currently the contemporary risks, aetiology and demographics of paediatric injury is unknown. Accurate understanding of this is vital to ensure appropriately targeted, effective injury prevention strategies and safeguarding. ${ }^{12}$

We aimed to characterise the incidence of trauma in children cared for within the London Major Trauma System (LMTS). The primary aim was to investigate the contemporary causes, risks and outcomes of injury for children in differing age cohorts. Second, we wished to evaluate safeguarding interventions associated with injured children.

\section{METHODS}

A prospective paediatric trauma evaluation was carried out over a 3-month period from February to April 2018. This time frame was chosen for consistency with previous trauma service evaluations within our system. ${ }^{13} 14$ The LMTS serves a wide geographical region. ${ }^{15}$ Four major trauma centres (MTCs) care for severely injured children and young people, while 34 trauma units (TUs) manage the less severely injured and provide safe onwards transfer for those requiring MTC interventions (online supplemental item 1). All MTCs and TUs within the LMTS were invited to participate in the evaluation. Engagement was optimised through meetings with network leads and the pan-London Paediatric Trauma group. Each site registered the evaluation with local clinical audit teams and had a dedicated consultant clinical lead and data collectors. Anonymised data were collected by clinicians on children who met at least one of the following inclusion criteria:

- Those who had a trauma team activation (online supplemental item 2).

- Those who were admitted or transferred (to MTC or quaternary service) due to trauma.
- Those who met National Institute for Health and Care Excellence criteria for CT head due to trauma (to capture those not otherwise included in trauma team activation criteria).

In view of the frequency with which children with minor injuries present to emergency departments the inclusion criteria were defined to identify the most severely injured children. Those with isolated minor injuries not requiring admission to hospital, advanced imaging or activating the hospitals trauma team response were not included. Patients were also excluded if they were found to have had a non-trauma cause for presentation or if their age exceeded the hospital's definition of a child. Prehospital deaths were not included in this project. The definition of 'paediatric' varies across the system, therefore, to reflect real world practice a child was defined as birth-16 years or birth-18 years as per individual hospital determination. Due to a lack of consensus in the literature, the study group decided to define adolescence as $\geq 12$ years of age.

A case report form was completed for each patient. Data were collected on age, gender, mechanism of injury, location of injury and injuries per body region. The primary outcome was in hospital mortality, secondary outcome was safeguarding concerns raised. Safeguarding children is defined by the UK government as 'preventing harm to children's health or development, taking action to enable all children and young people to have the best outcomes, to protect children from abuse and maltreatment and to ensure children grow up with the provision of safe and effective care. ${ }^{, 13}$ Safeguarding concerns could be raised by any clinical team member to highlight children or young people who may be at risk of harm. All children with safeguarding concerns were discussed in local psychosocial meetings as per local hospital policies and multidisciplinary team decisions were made regarding onward referral to social services and/or health visitor. Involvement of police and third sector organisations (including injury support and violence reduction programmes) were also captured. Children were followed up until they were discharged from hospital.

Descriptive statistics were used to compare differences between age cohorts ( $0-5$ years, $6-11$ years and $\geq 12$ years). These cohorts reflect significant periods of child development: infancy, childhood and adolescence. Continuous data are presented as medians with IQRs. Categorical data are presented with percentages.

Due to the nature of this work, patient and public involvement was not possible.

\section{RESULTS}

During the 3-month study period, 665 children were identified within the 22 participating hospitals (all MTC's and 18 TU's). Six were excluded due to non-trauma causes or age exceeding the hospitals definition of a child, leaving 659 children included in the evaluation. Of these, 52\% were cared for in an MTC and nearly two-thirds were 
Table 1 Demographics and injury characteristics of children and young people cared for in the London Major Trauma System February-April 2018

\begin{tabular}{|c|c|c|c|c|c|}
\hline & All children $(n=659)$ & $0-5$ years $(n=247)$ & $6-12$ years $(n=184)$ & $\geq 12$ years $(n=228)$ & $P$ value \\
\hline Male & $426(64.6)$ & $145(59.4)$ & $114(62.0)$ & 167 (73.2) & 0.540 \\
\hline Female & $233(35.4)$ & $102(40.6)$ & 70 (38.0) & $61(26.8)$ & 0.008 \\
\hline \multicolumn{6}{|l|}{ Mechanism of injury } \\
\hline Blunt & $596(90.4)$ & $243(98.3)$ & $175(95.1)$ & $178(78.1)$ & $<0.001$ \\
\hline Penetrating & $63(9.6)$ & $4(1.7)$ & $9(4.9)$ & 50 (21.9) & $<0.001$ \\
\hline Fall & $372(56.5)$ & $184(74.7)$ & 109 (59.2) & 79 (34.6) & $<0.001$ \\
\hline RTC & $83(12.6)$ & $13(5.3)$ & $35(19)$ & $36(15.8)$ & $<0.001$ \\
\hline Assault (all) & $63(9.5)$ & $6(2.4)$ & $5(2.7)$ & $52(22.8)$ & $<0.001$ \\
\hline Assault blunt & $22(3.3)$ & $6(2.4)$ & $4(2.2)$ & $12(5.3)$ & 0.133 \\
\hline Assault penetrating & $41(6.2)$ & $0(0)$ & $1(0.5)$ & $40(17.5)$ & $<0.001$ \\
\hline Other & $139(21.1)$ & $43(17.5)$ & $35(19)$ & $61(26.7)$ & 0.034 \\
\hline \multicolumn{6}{|l|}{ Location of injury } \\
\hline Home & $241(40.5)$ & $167(70.8)$ & $44(27.5)$ & $31(15.6)$ & $<0.001$ \\
\hline School & 98 (16.5) & $16(2.5)$ & $45(28.1)$ & $37(18.6)$ & $<0.001$ \\
\hline Street & $152(25.5)$ & $21(8.9)$ & $46(28.8)$ & $85(42.7)$ & $<0.001$ \\
\hline Other† & $102(17.1)$ & $32(13.6)$ & $25(15.6)$ & $46(23.1)$ & 0.026 \\
\hline \multicolumn{6}{|l|}{ Body region injured } \\
\hline Head & $252(39.6)$ & $121(51.9)$ & $65(36.1)$ & $66(29.5)$ & $<0.001$ \\
\hline Upper limb & $133(20.9)$ & $47(20.2)$ & $51(28.3)$ & $35(15.6)$ & 0.007 \\
\hline Lower limb & $113(17.7)$ & $26(11.2)$ & $35(19.4)$ & $52(23.2)$ & 0.002 \\
\hline Abdomino-thoracic & $25(3.9)$ & $1(0.4)$ & $1(0.5)$ & $23(10.3)$ & $<0.001$ \\
\hline Pelvis & $4(1.7)$ & $0(0)$ & $2(1.1)$ & $2(0.9)$ & 0.302 \\
\hline Spine & $19(8)$ & $1(0.4)$ & $8(4.4)$ & $10(4.5)$ & 0.002 \\
\hline Soft tissue & $26(11)$ & $17(7.3)$ & $2(1.1)$ & $7(3.1)$ & 0.005 \\
\hline Face & $23(9.7)$ & $13(5.6)$ & $8(4.4)$ & $2(0.9)$ & 0.021 \\
\hline Polytraumał & 27 (11.4) & $2(0.8)$ & $5(2.8)$ & $20(9.9)$ & $<0.001$ \\
\hline \multicolumn{6}{|l|}{ Management } \\
\hline MTC level care & $343(52)$ & $126(51.0)$ & $91(49.5)$ & $126(55.3)$ & 0.462 \\
\hline Required surgery & $194(29.4)$ & $50(20.2)$ & $72(39.1)$ & $72(31.5)$ & $<0.001$ \\
\hline Intensive care admission & $22(3.3)$ & $5(2.0)$ & 7 (3.8) & $10(4.4)$ & 0.329 \\
\hline
\end{tabular}

All data are presented as $\mathrm{n}(\%)$.

Denominator changes where data were missing: Mechanism of injury: $n=658$ (blunt vs penetrating $n=659$ ), $0-5$ years $n=246$. Location of injury: all $n=595,0-5$ years, $n=236,6-12$ years, $n=160,12+$ years, $n=199$. Body region injured: all $n=637,0-5$ years, $n=233,6-12$ years, $\mathrm{n}=180,12+$ years, $\mathrm{n}=224$.

$\mathrm{p} \leq 0.05$ was considered statistically significant, denoted in bold type.

${ }^{*}$ Other includes sports injury, burns, deliberate self-harm.

†Other includes parks/recreation facilities/playgrounds, sports grounds, soft play locations.

$\ddagger$ Polytrauma defined as injury to $>1$ body region.

MTC, major trauma centre; RTC, Road Traffic Collision.

male $(64.6 \%)$ (table 1$)$. The median age was 8.9 years (IQR: 3.75-13.96). A bimodal distribution of age was identified, with peaks of injury in the very young (0-2 years) and in adolescence (figure 1A). The youngest cohort ( $0-5$ years) was the largest $(37 \%)$ followed by $\geq 12$ years $(35 \%)$ then those aged $6-11$ years $(28 \%)$ (table 1$)$.

Across the entire cohort, penetrating trauma accounted for $9.6 \%$ of injuries, however, in adolescents, penetrating injury affected one in five $(21.9 \%)$. The predominant blunt mechanism of injury was falls $(56.5 \%)$. Road traffic collisions accounted for $12.6 \%$ of injuries. Over a quarter of injured children required an operative intervention $(29.4 \%)$ and admission to intensive care was 3.3\%. Mortality was $<1 \%$, with one child dying in the youngest cohort (table 1). The median hospital length of stay for survivors was 1 day (IQR 1-3).

Location of injury differed according to age (figure 1B). In younger children aged $0-5$ years, the majority were 
A

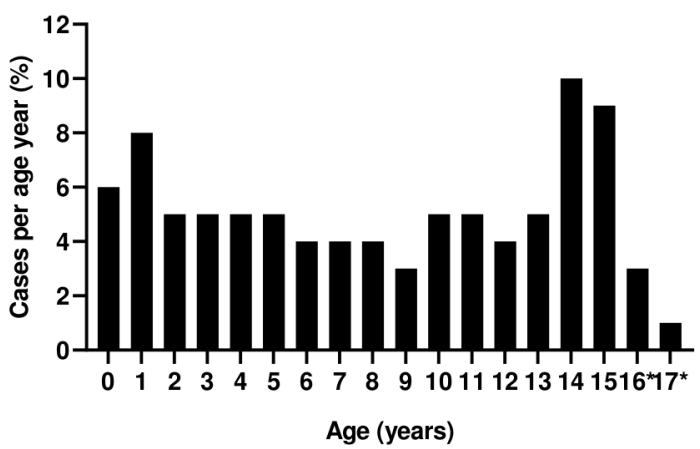

B

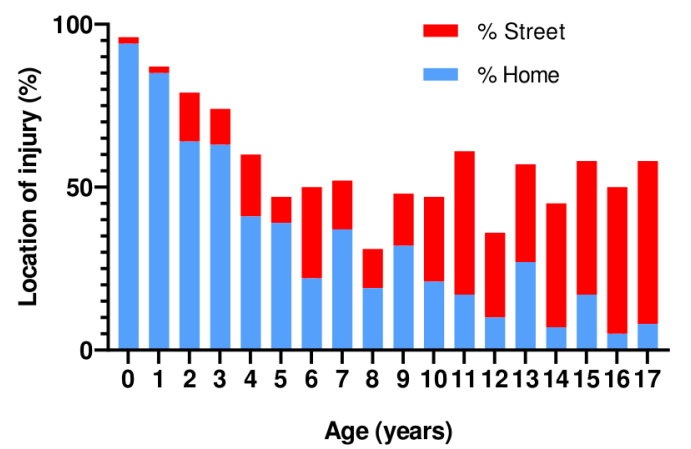

Figure 1 (A) Bar graph shows the percentage of cases per age in years.(B) Stacked bar graph shows the proportion of children injured at home or in the street per age in years. ${ }^{*} 16 / 17$ years old classified as paediatric in 2/22 hospitals

injured in their home $(70.8 \%)$. Almost three quarters of these younger children suffered falls $(74.7 \%)$, with more than half of this age group sustaining head injuries $(51.9 \%$ ) (table 1$)$. Conversely, adolescent injuries commonly occurred in the street and almost a quarter of this age group $(22.8 \%)$ were injured through interpersonal violence. Once again head injuries predominated however abdomino-thoracic trauma was greatest in adolescents compared with other age groups $(10 \%$ vs $<1 \%$, table 1 ). Polytrauma affected approximately $1 / 10$ th of the cohort $(11.4 \%)$ (table 1$)$.

Safeguarding concerns were raised in one in four injured children $(26.1 \%$ ) (table 2). These were identified in all age groups but bimodal peaks of concern were observed in the youngest $(30.4 \%)$ and oldest children $(33.3 \%)$ (figure 2A). Overall, almost one in three children $(30.6 \%)$ were referred to social services or the health visitor following their injury (table 2) with similar bimodal peaks (figure 2B). Forty-nine (19.8\%) children in the $0-5$ years cohort were under 1 year old, of these $45 \%{ }^{16}$ had safeguarding concerns and $63 \%$ (31) were referred for social services or health visitor input (figure 2A,B). Almost a quarter of adolescents required input from the police and third sector organisations (table 2) with a stepwise increase observed from age 13 years onwards.

\section{DISCUSSION}

This project has characterised the contemporary incidence and mode of traumatic injury for children and young people within the LMTS through a prospective evaluation of those presenting to a trauma system not selected by Injury Severity Score (ISS) or length of stay. This includes data captured for all children and young people presenting with an injury or mechanism severe enough to require trauma team activation, admission or transfer for ongoing care and/or CT head. These data offer a contemporary overview of paediatric trauma within a region and help to fill existing knowledge gaps present due to the current national registry inclusion criteria. Data were captured from children and young people managed in both MTC and TU settings, including both rural and inner city populations using the same core methodology as previous trauma service evaluations. ${ }^{145}$

Variation exists in the pattern of injuries seen in childhood and adolescence. Differences were seen in the location of injuries, with preschool age children most likely to be injured in their homes compared with older children and adolescents, who were most likely to be injured in the street. Traditional mechanisms of trauma associated with children and young people, such as road traffic collisions, were less evident, with falls the primary cause of

\begin{tabular}{|c|c|c|c|c|c|}
\hline & All children $(n=659)$ & $0-5$ years $(n=247)$ & $6-12$ years $(n=184)$ & $\geq 12$ years $(n=228)$ & $P$ value \\
\hline Mortality & $1(0.15)$ & $1(0.4)$ & $0(0)$ & $0(0)$ & 0.434 \\
\hline Safeguarding concern & $172(26.1)$ & $75(30.4)$ & $21(11.4)$ & $76(33.3)$ & $<0.001$ \\
\hline Referral to HV/SS & $202(30.6)$ & 97 (39.3) & 30 (16.3) & 75 (32.9) & $<0.001$ \\
\hline Police involvement & $84(12.7)$ & $13(5.3)$ & $18(9.8)$ & $53(23.2)$ & $<0.001$ \\
\hline $\begin{array}{l}\text { Third sector/external } \\
\text { agency involvement }\end{array}$ & $61(9.3)$ & $4(1.6)$ & $4(2.2)$ & $53(23.2)$ & $<0.001$ \\
\hline Hospital stay (days)* & $1(1-3)$ & $1.5(1-2)$ & $1(1-4.5)$ & $2(1-5)$ & $<0.001$ \\
\hline
\end{tabular}

$\mathrm{p} \leq 0.05$ was considered statistically significant, denoted in bold type.

${ }^{*}$ All data are presented as $\mathrm{n}(\%)$ except for hospital stay (median with IQR).

$\mathrm{HV}$, health visitor; SS, social services. 
A

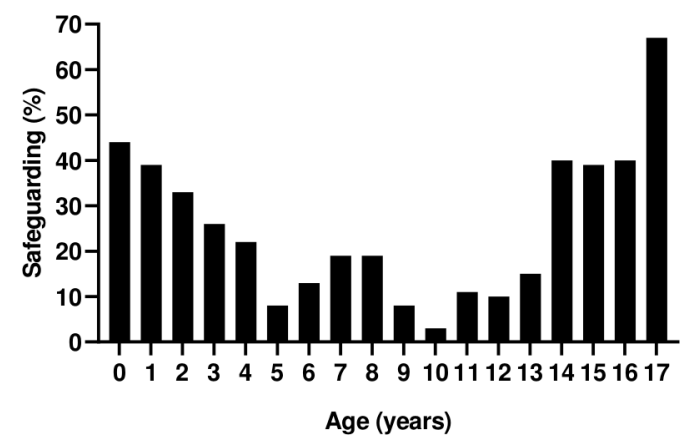

B

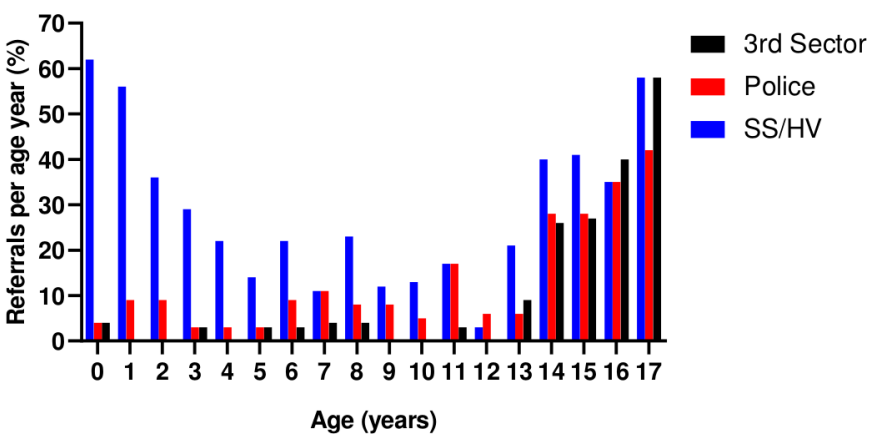

Figure 2 (A) Bar graph shows the proportion of safeguarding referrals made per age in years. (B) Bar graph shows the referrals to social services/health visitor (SS/HV) and involvement of police and third sector organisations per age in years.

injury in the younger cohort while a demonstrable rise in interpersonal violence and penetrating injuries was observed in adolescence. Head injuries predominated across all age groups with over half of the younger children affected. The higher rate of abdomino-thoracic injuries seen in adolescents is thought to be associated with increased penetrating trauma in this group (online supplemental table 1). A quarter of the children and young people included in this evaluation had significant safeguarding concerns raised and one in four adolescents required input from police and/or third sector organisations. Mortality was low $(0.2 \%)$ contrasting with previous reports of $8.8 \%$ in severely injured ${ }^{15}$ and $3.1 \%$ in moderately injured children and we are unable to account for this. ${ }^{5}$ Deaths may have occurred at scene, not captured by this project. Our cohort contained children and young people of all injury severities and was not limited by TARN inclusion criteria, other factors such as the maturation of the trauma system may have contributed to increased survival. ${ }^{14}$

This study highlights differences in how children and adolescents sustain traumatic injury. In our cohort, the predominant cause of injury in children and young people was falling. This was greater in younger children, a group most at risk of injury in their home environment. Injury in the home is common and offers opportunity for injury prevention. ${ }^{17}$ Children aged $0-5$ years were most likely to suffer head injuries. Previous reports have suggested toddlers, aged 1-4 years, have the lowest rates of head injury, however, such reports have limited their data to moderate to severe injury. ${ }^{5}$ By expanding our cohort, we highlight the risk of head injuries in this age group, most sustained as the result of accidental falls. The consequences of falls in this age group, particularly those with mild traumatic brain injury, are increasingly appreciated, with evidence suggesting lasting cognitive effects for the individual and economic effects for society. ${ }^{8}$ Understanding the true burden and the avoidable nature of these injuries makes head injury prevention a paediatric public health priority.

Interpersonal violence poses a serious risk to adolescents $^{28}$ with one-fifth sustaining injuries due to alleged assault, the vast majority of which were penetrating. This equates to one child every 2 days suffering penetrating injuries across our region. Reported rates of paediatric penetrating injuries have previously been much lower, $2.2 \% .^{5}$ Our findings highlight how current TARN eligibility criteria may underestimate the reality of paediatric penetrating injury as many will stay in hospital for less than 3 days or not require critical care admission. Accurate understanding of the true volume of these injuries is vital if we are to effectively target resources for injury prevention. Prevention strategies must recognise the involvement of younger children and capitalise on the potential for intervention in this group to break the cycle of children later presenting as young adults with lifethreatening injuries.

Safeguarding remains a major concern in contemporary paediatric trauma care. The need for safeguarding was raised in a quarter of cases and this was highest in both the youngest group and adolescents. It is known infants under 1 year are at the highest risk of non-accidental injury (NAI). ${ }^{18}$ Educational programmes introduced to aid parents to develop coping strategies for crying babies have been highlighted as important in reducing the risk of these youngest and most vulnerable children. ${ }^{19-21}$ The bimodal distribution of safeguarding concerns also highlights the need to consider the unique safeguarding challenges faced by adolescents. ${ }^{22}$ Our findings question what effective modern day safeguarding in children and adolescents looks like. Safeguarding children and young people has traditionally been viewed as a family experience, with support for caregivers being of paramount importance in preventing harm to children. The same view is not currently taken for children or adolescents as the victims of interpersonal violence. Historically effort has focused on the prevention and identification of NAI, often at the hands of caregivers. ${ }^{16}$ Yet safeguarding practices must also reflect the contemporary risks of intentional interpersonal violence and the prevention of avoidable harm from unintentional injury which may impact a child's ability to reach their full potential. Early years interventions may be vital in reducing these risks. ${ }^{23}$

Limitations exist in this project. First, some of the smaller TUs were unable to participate due to service commitments therefore cases will have been 
missed. However, each of the four MTCs participated, suggesting that the most severely injured children were included. Our definition of adolescents and the varying upper age limit may not reflect paediatric practice elsewhere, however, this illustrates the real world variation seen across different settings. Although the LMTS serves both urban and rural populations, we acknowledge these findings may not be representative of all trauma networks. The high proportion of penetrating injuries seen in our cohort may not currently represent the entire UK, however, with the rising incidence of violence and county lines safeguarding issues, it is essential to raise awareness of this and the need for prevention. The project ran for a period of 3 months, the time frame chosen in line with previous trauma service evaluations, therefore, seasonal differences in attendance may not be accounted for. ISS was not collected for all included children therefore overall analysis of injury severity was not possible. This may also affect mortality comparisons, however only one child died during our study period. Some physician or institutional variations may exist between hospitals however LMTS has paediatric trauma guidelines which promote standardisation across the settings. Finally, children whose injuries or mechanism were not severe enough to meet the inclusion criteria were not included, incorporation of these may have identified other patterns of injury which may yield further opportunities for injury prevention.

By expanding our lens, this evaluation has bridged a gap in understanding paediatric trauma, however, many learning opportunities remain. Further research would ideally include a yearlong, national study, removing seasonal and geographical variation, to include data capture on prehospital deaths, emergency department discharges and longer-term outcomes.

Finally, injured children should not be thought of in isolation. Consideration must be given to the families and wider support networks which play a vital role in prevention and in rehabilitation. As such, opportunities for patient and family engagement in future work and codevelopment of injury prevention strategies must be at the forefront.

\section{CONCLUSION}

This evaluation has described the changing demographics of contemporary paediatric trauma and has highlighted the variance in injury patterns in young children and adolescents. Importantly, it has highlighted differences in actual rates of injuries compared with those levels reported from current national registry data. The importance of a contemporary understanding of the real risks facing children in the 21st century cannot be underestimated if we are to safeguard our future generations effectively. The results provide an opportunity to reassess our current approach to injury prevention, child and adolescent safeguarding, and public health campaigns for child safety.

\section{Author affiliations}

${ }^{1}$ Paediatric Surgery, Barts Health NHS Trust, London, UK

${ }^{2}$ Centre for Trauma Sciences, The Blizard Institute, Queen Mary University, London, UK

${ }^{3}$ Paediatric Surgery, Queen Mary University of London, London, UK

${ }^{4}$ Paediatric Surgery, St George's University Hospitals NHS Foundation Trust, London, UK

${ }^{5}$ Paediatric Surgery, King's College Hospital, London, UK

${ }^{6}$ Emergency Medicine, Imperial College Healthcare NHS Trust, London, UK

${ }^{7}$ Trauma and Vascular Surgery, Barts Health NHS Trust, London, UK

${ }^{8}$ Paediatric Intensive Care, Barts Health NHS Trust, London, UK

${ }^{9}$ Paediatric Anaesthesia, Barts Health NHS Trust, London, UK

Collaborators Paediatric Evaluation of the London Trauma System (PELoTS) Collaborators: The London Trauma System: Derek Hicks, Ross Davenport, Leila Razavi, Emily Beddows, Ben Anthony, Joseph Davies; Healthy London Partnership: Giles Armstrong, Fran White; St Georges Hospital: Kevin Enright, Owen Morgan; Kings College Hospital: Duncan Bew, Pradeepa Venkatesan, Robert Bentley; St Mary's Hospital: Nic Alexander, Varsha Nemarugommula, Clare Rees; The Royal London Hospital: Kyla Ng, Anne Chua; The Whittington Hospital: Rachel Landau, Joanne Flanagan, Anoushka Neal, Bethany McGhee; Barnett Hospital: Christian Solomonides, St Thomas Hospital: Nicola McDonald, Nick Ward, Lewisham Hospital: Tina Sajjanhar, Sophie Keers, Jessica Smith, Lucy-Rose Howroyd; Queen Elizabeth Hospital: Hayder Hassan, Atul Kapur, Mark Chamberlain; Tunbridge Wells Hospital: Matt Milner, Carol Still; Chelsea and Westminster Hospital: Munther Haddad, Jessica Ng; Watford General Hospital: Solomon Kamal-Uddin, Sarah Hickin-Yocoub; Southend Hospital: Ravi Kuppuswamy, Nazneen Hoque, Aral Jamalfar; Queens Hospital: Ignatius Postma, Akbar Hussain; Newham Hospital: Ruchin Agrawal, Lottie Elton, Cyrusia Adeyemi; North Middlesex Hospital: Gayle Hann, Charlotte Clemments, Sile Egan, Natalie Clarke; Kent and Canterbury Hospital: Fernando Candal Carballido; St Peters Chertsey: Fiona McCarthy, Lucy Crossman; Princess Royal University Hospital: Gabrielle Budd, Angus Fitchie, Timothy Scott, Panamoottil Anil Kumar.

Contributors CE: chief investigator, project design, data collection, analysis, interpretation and write up, drafting and critically appraising work, final approval, accountability for work and guarantor. EC: project design, data collection, analysis, interpretation and write up, drafting and critically appraising work, final approval, accountability for work. SM: project design, data collection, analysis, critically appraising work, final approval, accountability for work. DR: project design, data collection, analysis, critically appraising work, final approval, accountability for work. EM: project design, data collection, analysis, critically appraising work, final approval, accountability for work. RS: project design, data collection, analysis, critically appraising work, final approval, accountability for work. KB: project design, analysis, critically appraising work, final approval, accountability for work. $\mathrm{NE}$ : project design, data collection, analysis, interpretation and write up, drafting and critically appraising work, final approval, accountability for work. SC: project design, data collection, analysis, interpretation and write up, drafting and critically appraising work, final approval, accountability for work. BO'N: project design, data collection, analysis, interpretation and write up, drafting and critically appraising work, final approval, accountability for work.

Funding The authors have not declared a specific grant for this research from any funding agency in the public, commercial or not-for-profit sectors.

Competing interests The authors declare: organisational support (provision of online secure platform for data sharing, SLACK) was provided by the Healthy London Partnership; no financial relationships with any organisations that might have an interest in the submitted work in the previous 3 years, no other relationships or activities that could appear to have influenced the submitted work.

Patient and public involvement statement Due to the nature of this work patient and public involvement was not possible.

Patient consent for publication Not applicable.

Ethics approval This project was conducted by clinical staff within each of the four trauma networks forming the LMTS and met the criteria of a service evaluation, therefore, ethical approval was not required. 
Provenance and peer review Not commissioned; externally peer reviewed.

Data availability statement Data are available on reasonable request. Deidentified data can be made available upon suitable request for further work. All requests to access the data will be reviewed by the chief investigator and regional leads.

Supplemental material This content has been supplied by the author(s). It has not been vetted by BMJ Publishing Group Limited (BMJ) and may not have been peer-reviewed. Any opinions or recommendations discussed are solely those of the author(s) and are not endorsed by BMJ. BMJ disclaims all liability and responsibility arising from any reliance placed on the content. Where the content includes any translated material, BMJ does not warrant the accuracy and reliability of the translations (including but not limited to local regulations, clinical guidelines, terminology, drug names and drug dosages), and is not responsible for any error and/or omissions arising from translation and adaptation or otherwise.

Open access This is an open access article distributed in accordance with the Creative Commons Attribution Non Commercial (CC BY-NC 4.0) license, which permits others to distribute, remix, adapt, build upon this work non-commercially, and license their derivative works on different terms, provided the original work is properly cited, appropriate credit is given, any changes made indicated, and the use is non-commercial. See: http://creativecommons.org/licenses/by-nc/4.0/.

ORCID iD

Ceri Elbourne http://orcid.org/0000-0002-7858-2536

\section{REFERENCES}

1 Wolfe I. Why children die : death in infants, children and young people in the UK Part A 2014

2 Vulliamy P, Faulkner M, Kirkwood G, et al. Temporal and geographic patterns of stab injuries in young people : a retrospective cohort study from a UK major trauma centre. BMJ 2018:1-6.

3 Trust SG. St. Giles Trust [Internet], 2019. Available: https://www. stgilestrust.org.uk/\%0D

4 Nielsen JW, Shi J, Wheeler K, et al. Resource use in pediatric blunt and penetrating trauma. J Surg Res 2016;202:436-42.

5 Jones S, Tyson S, Young M, et al. Patterns of moderate and severe injury in children after the introduction of major trauma networks 2019:366-71.

6 Department of Transport UG. Reported road casualties in Great Britain : 2017 annual report 2018.
7 Trust CAP. Falls [Internet], 2019. Available: https://www.capt.org.uk/ falls

8 Mclsaac KE, Moser A, Moineddin R, et al. Association between traumatic brain injury and incarceration: a population-based cohort study. C Open 2016;4:E746-53.

9 Health RC of $\mathrm{P}$ and C. State of Child Health: Youth violence [Internet], 2021. Available: https://stateofchildhealth.rcpch.ac.uk/ evidence/injury-prevention/youth-violence/

10 BYCYSC. Our generations epidemic: knife crime. 2019. London, 2019.

11 Redthread. Redthread [Internet], 2019. Available: https://www. redthread.org.uk/\%0D

12 TARN. Pan London Trauma Syst 2018.

13 Commision TC. Safeguarding and protecting people for charities and trustees 2017.

14 Cole $E$, Lecky $F$, West $A$. The impact of a Pan-regional inclusive trauma system on quality of care $2015 ; 264: 188-94$.

15 Confi N, Outcome P. Trauma : Who cares ? A report of the National Confi dential Enquiry into Patient Outcome and Death 2007.

16 Radford L, Corral S, Bradley C, et al. Child abuse and neglect in the UK today 2011.

17 ROSPA, 2020. Available: https://www.rospa.com/home-safety/ advice/accidents-to-children

18 Davies FC, Coats TJ, Fisher R, et al. A profile of suspected child abuse as a subgroup of major trauma patients. Emerg Med $J$ 2015;32:921-5

19 Barr RG, Bis MB, Fujiwara T. Brant R. and behaviour about crying and Shaken baby syndrome? A randomized controlled trial 2009;180:727-33.

20 Barr RG, Rajabali F, Aragon M, et al. Education about crying in normal infants is associated with a reduction in pediatric emergency room visits for crying complaints.

21 Rg B, Barr M, Rajabali F, et al. Eight-year outcome of implementation of abusive head trauma prevention 2018.

22 Littler, Nadine (Senior lecturer in nursing, Department of Nursing, Health and Professional Practice, University of Cumbria, Lancaster E. Adolescent safeguarding: a review of the literature [Internet], 2021. Available: https://journals.rcni.com/nursing-children-andyoung-people/evidence-and-practice/adolescent-safeguarding-areview-of-the-literature-ncyp.2019.e1177/abs

23 System LMT. Violence Reduction - Centre For Trauma Sciences [Internet], 2021. Available: https://www.c4ts.qmul.ac.uk/londontrauma-system/violence-reduction 